\title{
SIMPEC: Sistema de Manutenção Preventiva para Equipamentos de Climatização
}

\author{
Antônio E. Pereira ${ }^{2}$, Isabela F. França ${ }^{1}$, Melyssa M. G. Silva ${ }^{2}$, \\ Bruna M. O. S. Cordeiro ${ }^{1}$, Iwens. G. Sene Junior ${ }^{1}$, Renato F. Bulcão-Neto ${ }^{1}$ \\ ${ }^{1}$ Instituto de Informática - Universidade Federal de Goiás (UFG) \\ Caixa Postal 74001-970 - Goiânia - GO - Brasil \\ ${ }^{2}$ Escola de Engenharia Elétrica, Mecânica e de Computação - UFG \\ Caixa Postal 74605-010 - Goiânia - GO - Brasil \\ antoniopereiraediscente.ufg.br,brunacordeirodinf.ufg.br \\ iwens@ufg.br, rbulcao@ufg.br
}

\begin{abstract}
Poor maintenance of air conditioning equipment is a potential cause of problems to human health. Therefore, there is a need for constant preventive monitoring of indoor climate-controlled and collective use environments. This work presents the Preventive Maintenance System for Air Conditioning Equipment (SIMPEC), an Internet of Things solution composed of sensors and a web application deployed in a university research laboratory.
\end{abstract}

Resumo. A má condução da manutenção de aparelhos de climatização é um potencial causador de problemas à saúde humana. Logo, há uma necessidade de constante monitoramento preventivo de ambientes fechados climatizados e de uso coletivo. Este trabalho apresenta o Sistema de Manutenção Preventiva para Equipamentos de Climatização (SIMPEC), uma solução de Internet das Coisas composta de sensores e uma aplicação web em operação em um laboratório de pesquisa universitário.

\section{Introdução}

Dentre os principais fatores que contribuem para a má qualidade do ar interno está a falta de circulação de ar. Como consequência, tem-se o aumento da concentração de poluentes nocivos à saúde que, dentre outras, pode causar a Síndrome dos Edifícios Doentes (SED). Essa síndrome caracteriza-se por um conjunto de sintomas causados ou estimulados pela poluição do ar em espaços fechados, como dor de cabeça, fadiga, prurido e ardor nos olhos, irritação de nariz e garganta, anormalidades na pele e falta de concentração [Norhidayah et al. 2013, Carvalho 2016].

Um potencial e comum agravante da SED é a baixa manutenção de aparelhos de climatização [Menêz et al. 2018]. É imprescindível que a manutenção desses aparelhos seja feita de forma contínua e preventiva, com o acompanhamento do estado de filtros e de dutos de ventilação e da condição geral das máquinas. A negligência da manutenção implica diretamente na qualidade do ar desses espaços [Teixeira et al. 2005].

A Portaria $N^{\circ} 3.523 / 98$ instituiu a necessidade de um Plano de Manutenção, Operação e Controle (PMOC) para padronização de processos de limpeza, conservação 
e manutenção de sistemas de climatização [Ministério da Saúde 2017]. Todos os parâmetros incluídos no PMOC são cruciais para o funcionamento ideal e seguro, englobando o exame de todos os componentes do equipamento, além da verificação e limpeza do ambiente de localização das máquinas.

Este trabalho de iniciação científica faz parte de um projeto de pesquisa em andamento, cujo objetivo é desenvolver um Sistema de Manutenção Preventiva para Equipamentos de Climatização (SIMPEC). O sistema é composto por duas partes, uma solução IoT (do inglês Internet of Things) para monitoramento da qualidade do ar e uma aplicação Web para informar e auxiliar preventivamente o órgão responsável pela manutenção dos aparelhos de climatização da Universidade Federal de Goiás (UFG).

Este artigo está organizado da seguinte maneira: o projeto e o desenvolvimento da solução IoT estão descritos, respectivamente, nas Seções 2 e Seção 3, e a Seção 4 relata o estado atual desta pesquisa de iniciação científica.

\section{Solução IoT para monitoramento da qualidade do ar}

A Internet das Coisas refere-se a uma rede de objetos físicos (ou coisas) incorporados a sensores, software e outras tecnologias. O objetivo é conectar e trocar dados com outros dispositivos e sistemas por meio da Internet [Ashton et al. 2009]. Assim, utilizou-se sensores conectados em uma placa de prototipagem para a realização do monitoramento da qualidade do ar em um ambiente climatizado. O protótipo desenvolvido foi denominado AirPure e está ilustrado na Figura 1, onde é possível visualizar a case impressa em 3D e os componentes utilizados.

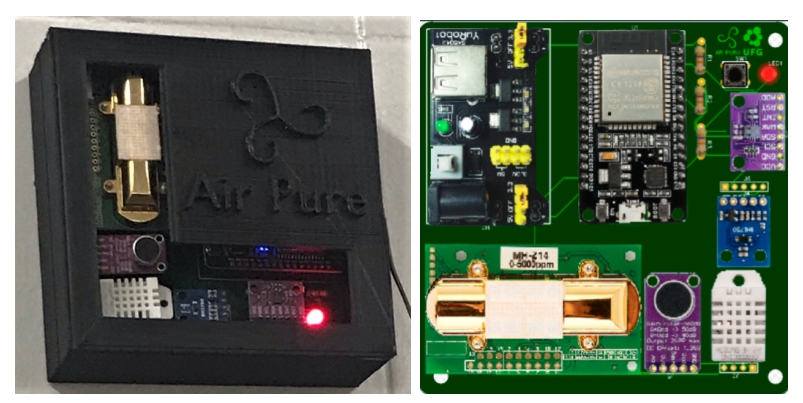

Figura 1. Protótipo AirPure.

Em um ambiente climatizado, diversos fatores contribuem para a elevação da poluição interna [Teixeira et al. 2005]. Após um levantamento bibliográfico, identificaram-se os seguintes fatores relacionados à qualidade do ar: umidade relativa, temperatura, dióxido de carbono $\left(\mathrm{CO}_{2}\right)$ e compostos orgânicos voláteis totais (COVT). A Tabela 1 apresenta os fatores monitorados por cada sensor, e os valores limites, máximos e mínimos, conforme legislações seguidas.

Uma placa de circuito impresso foi utilizada para a conexão entre os sensores e o módulo NodeMCU ESP32S, utilizado para processamento e comunicação, conforme Figura 1. A ESP332S trata-se de um chip com baixo consumo de energia que possui capacidade de comunicação via Wi-Fi e dual-mode Bluetooth. Os dados são devidamente processados, analisados e armazenados em banco de dados para que possam ser exibidos, em tempo real, para o usuário final. 
Tabela 1. Fatores Monitorados pelo AirPure.

\begin{tabular}{llccl}
\hline Sensor & Fator & Máximo & Mínimo & Legislação \\
\hline DHT22 & Umidade Relativa & $65 \%$ & $35 \%$ & Anvisa - No 09/2003 \\
DHT22 & Temperatura & $26^{\circ} \mathrm{C}$ & $20^{\circ} \mathrm{C}$ & Anvisa - N $09 / 2003$ \\
MH-Z14A & $\mathrm{CO}_{2}$ & $1000 \mathrm{ppm}$ & $400 \mathrm{ppm}$ & Anvisa - N $09 / 2003$ \\
CCS811 & $\mathrm{COVT}$ & $500 \mu \mathrm{g} / \mathrm{m}^{3}$ & - & Diretrizes da OMS \\
\hline
\end{tabular}

\section{Sistema de Manutenção Preventiva para Equipamentos de Climatização}

O SIMPEC foi desenvolvido para auxiliar técnicos e administradores de infraestrutura de climatização da UFG. Os dados coletados em tempo rea, são disponibilizados em nuvem para a visualização em desktop ou mobile, com possibilidade de notificações personalizadas via e-mail ou Telegram. O usuário é capaz de visualizar todos os parâmetros monitorados pelos sensores, gerar relatórios de qualidade do ar e cadastrar manutenções em aparelhos de ar condicionado.

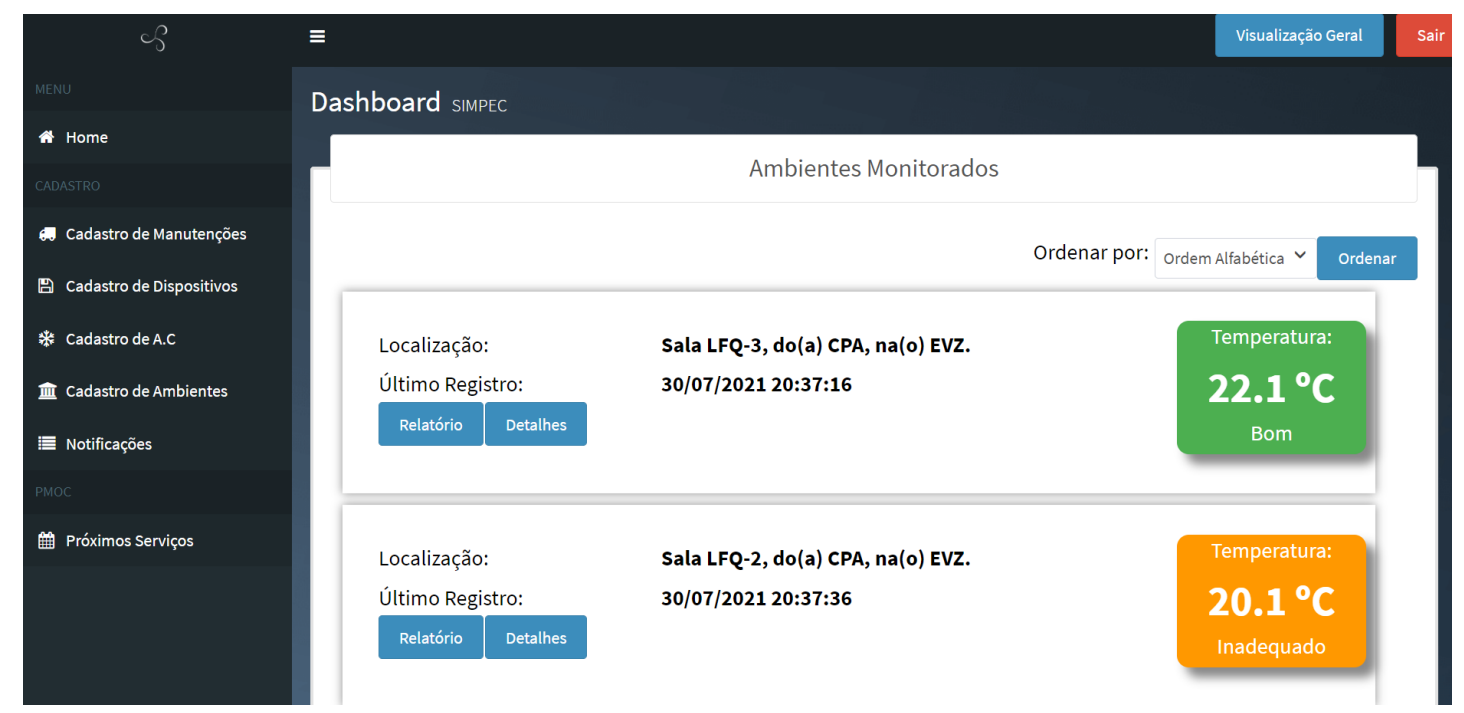

Figura 2. Tela Inicial do sistema SIMPEC.

A Figura 2 apresenta a tela inicial do sistema com os valores de temperatura para cada ambiente monitorado. O SIMPEC realiza uma apresentação detalhada, conforme a Figura 3, e gera um relatório contendo informações, como ocupação máxima do local, modelo e capacidade do aparelho de ar-condicionado, manutenções realizadas ou agendadas, valores médios, máximos, mínimos e desvio padrão de todos os fatores monitorados e visualização gráfica.

Uma escala de cores indica se os valores estão dentro do estabelecido, conforme Tabela 1: verde e vermelho simbolizam valores dentro e fora dos limites, e laranja, aqueles valores próximos dos limites. O layout inicial do sistema foi definido após reuniões com a coordenação de equipamentos da Secretaria de Infraestrutura (SEINFRA) da UFG.

Pelo menu lateral mostrado na Figura 2, pode-se cadastrar um novo local a ser monitorado, fornecendo informações físicas do ambiente, vinculando uma solução Air- 


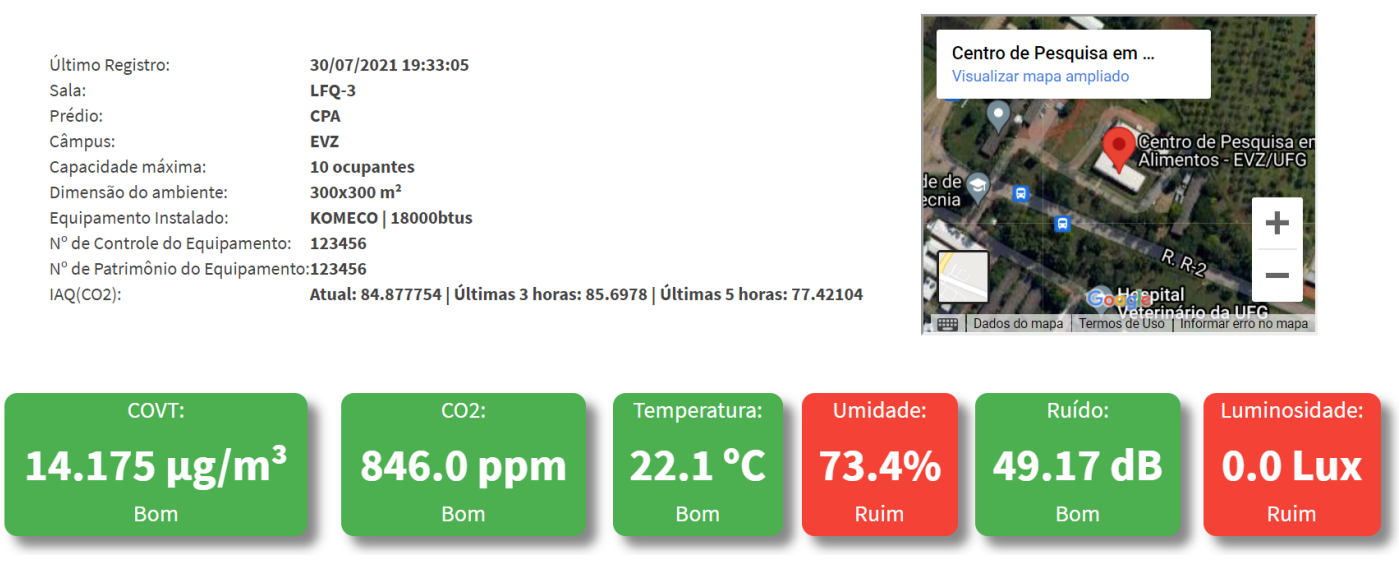

Figura 3. Visualização detalhada de um ambiente monitorado.

Pure para coleta de dados e informações do aparelho de climatização. Desse modo, todo o sistema pode ser configurado e atualizado pela aplicação Web.

\section{Estado atual da pesquisa}

Atualmente, dois dispositivos AirPure estão instalados em um laboratório da Escola de Veterinária e Zootecnia da UFG, responsável pelo controle de qualidade de alimentos. Visa-se monitorar agentes ligados à qualidade do ar e a riscos ocupacionais, como ruído e iluminação. Já a SEINFRA da UFG tem monitorado os dados coletados para apoiar a manutenção preventiva dos equipamentos de climatização desse laboratório.

\section{Referências}

Ashton, K. et al. (2009). That 'internet of things' thing. RFID journal, 22(7):97-114.

Carvalho, M. H. A. d. (2016). Avaliação da qualidade do ar interior em ambientes acadêmicos: um estudo de caso. Master's thesis, Centro de Ciências Sociais Aplicadas, Universidade Federal do Rio Grande do Norte, Natal, Brasil.

Menêz, M. et al. (2018). Benefícios da manutenção preventiva para o sistema de climatização do isecensa. Exatas \& Engenharias, 8(22).

Ministério da Saúde (2017). Portaria no 3.523, de 19 de dezembro de 2017.

Norhidayah, A. et al. (2013). Indoor air quality and sick building syndrome in three selected buildings. Procedia Engineering, 53:93-98.

Teixeira, D. B. et al. (2005). Síndrome dos edifícios doentes em recintos com ventilação e climatização artificiais: Revisão de literatura. In VIII Congresso Brasileiro de Defesa do Meio Ambiente, pages 1-11, Rio de Janeiro, RJ, Brasil. 